
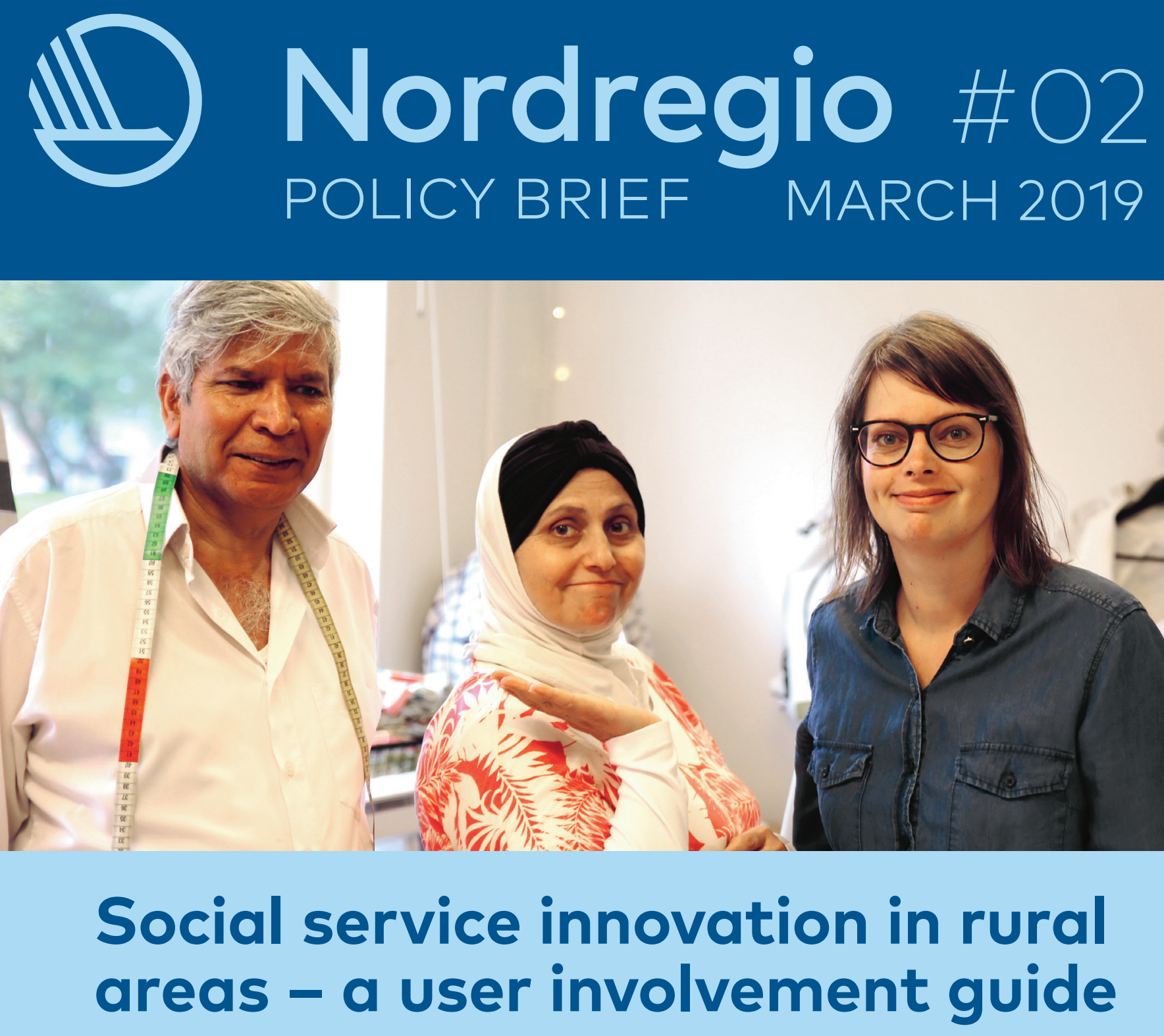

High-quality service provision in rural areas is becoming increasingly difficult due to social and demographic challenges, exacerbated by welfare cuts. Members of disadvantaged groups, such as the long-term unemployed, migrants and people with disabilities, may be particularly affected by shrinking social services as they often lack the resources to influence or compensate for this loss. How can user involvement in service design and delivery contribute to addressing these challenges? What is needed to make service-user involvement work? This policy brief, based on the learnings from the SEMPRE project financed by the Interreg Baltic Sea Region Programme, gives an introduction to a user guide that has been developed to empower disadvantaged groups in rural areas.

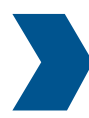

Innovative approaches are required if we are to sustain and improve welfare services, in terms of both solutions to address the challenges and the process of addressing them (Lindberg, 2018). If this is not done, the delivery of social services, especially in rural and remote areas, cannot be sustained in the long run (Copus et al., 2017) and the attractiveness and liveability of rural areas will further decrease.

User involvement in the service design process has been widely promoted as a central approach in 
the social service innovation paradigm because of its potential to play a key role in adapting quickly and flexibly to changing demands and to make social services more effective, inclusive, efficient and sustainable (Copus et al., 2017).

There are two perspectives on user involvement. The first is supported by New Public Management, which emphasises efficiency and cost-effectiveness. According to this line of thought, service users are customers of the public sector, following the market logic of choice but without sufficient monitoring, control and decision-making mechanisms concerning resources, design and delivery. The second has a strong democratic/citizenship orientation and aims to erase/ diminish exclusion and oppression, and to redistribute power (Beresford, 2016). By involving vulnerable groups in society and making their voices heard and recognised, a number of benefits can be achieved.

On the one hand, there is a growing recognition that because of users' direct experiences of using services, they have a better insight into what works, which can help to develop more targeted and higher quality services. By designing services and solutions with the users and not for them, better results can be expected, including increased efficiency in terms of services and the use of resources, a potentially lower cost of service provision and/or an improved capacity to meet service users' needs.

On the other hand, active involvement of service users in social service design and delivery can also contribute to their personal empowerment by giving them an opportunity to develop their innate potential and gain the skills and sense of self-worth that come with the increased ability to influence both society and their own lives.

Despite the acknowledged benefits of user involvement, experiential knowledge and user perspectives are not yet regular practice in social service design. Moreover, the dissemination of innovative service provision processes to rural areas has been relatively poor, and many organisations are still applying a rather traditional approach to service provision. The co-creation of social services jointly by users and service providers has been one of the practical outcomes of the SEMPRE project (read more in the info box).

\section{GOOD PRACTICES FOR USER INVOLVE- MENT IN SERVICE DESIGN AND DELIVERY IN THE BALTIC SEA REGION}

More than 30 micro projects were developed as part of the SEMPRE project 2016-2019. These are smallscale projects that were initiated at least partly by service users, with service providers acting as facilitators rather than drivers of this process, in a threestage process:

1. Needs assessment phase: Gathering service users in a group setting and working out and prioritising their service needs and wishes in a participatory manner.

2. Service design: Developing ideas for new, or renewing existing, social services that address the needs compiled in phase 1, initiating user-driven 'micro projects' that have the aim of delivering these new services.

3. Entrepreneurial support for micro projects: Assisting and consulting the initiators of the micro projects to find the right organisational format (e.g. social enterprise, cooperative, NGO) and draw up a business plan, enabling the micro projects to operate independently and without external financing in the long run. Some of the examples are presented below.

The Tailor cooperative in Luleå, Sweden:
combining the integration of migrants into
work and the production of sustainable textiles The Tailor cooperative in Luleå started as a micro project co-created by migrant women and a local tailor. The process of developing a cooperative was facilitated by the Coompanion Norrbotten (a SEMPRE project partner promoting social business), which helped to develop a business plan and find partners and finance and provided continuous mentorship support and education on social entrepreneurship. The cooperative now employs six people. It provides tailoring services to both private and public customers and job training for unemployed people in the local area. The cooperative has a sales agreement with the grocery cooperative, Coop, regarding reusable fruit and vegetable bags. Read more about this and other micro projects in the compilation of SEMPRE micro projects. ${ }^{2}$

The figure on next page illustrates the timeline and the process of developing a tailor's cooperative in Luleå.

THE SEMPRE PROJECT (Social Empowerment in Rural Areas), funded by the Interreg Baltic Sea Region Programme 2016-2019, aimed to enhance innovative forms of social service delivery in rural areas of the Baltic Sea Region. SEMPRE promoted the involvement of disadvantaged groups, such as single parents, older adults, people with disabilities, disadvantaged young people, the longterm unemployed and migrants in service provision and service innovation. Nordregio's main tasks in the project were to compile the Empowerment Handbook ${ }^{1}$, which presents tools and methods for empowering service users and involving them in the service design and delivery process, and to make policy recommendations based on the project results. 
The success of the initiative can be attributed to a number of factors including a thorough needsassessment where the actual needs, talents and ideas of the service-user group (migrants) are identified. Training, mentoring, and knowledge of different funding schemes were important factors for establishing the micro project and to later transform it into a cooperative with six employees. The cooperation and support from the local empowerment network (LEN) and other actors was crucial in all steps of the process.

LEN Stakeholders:

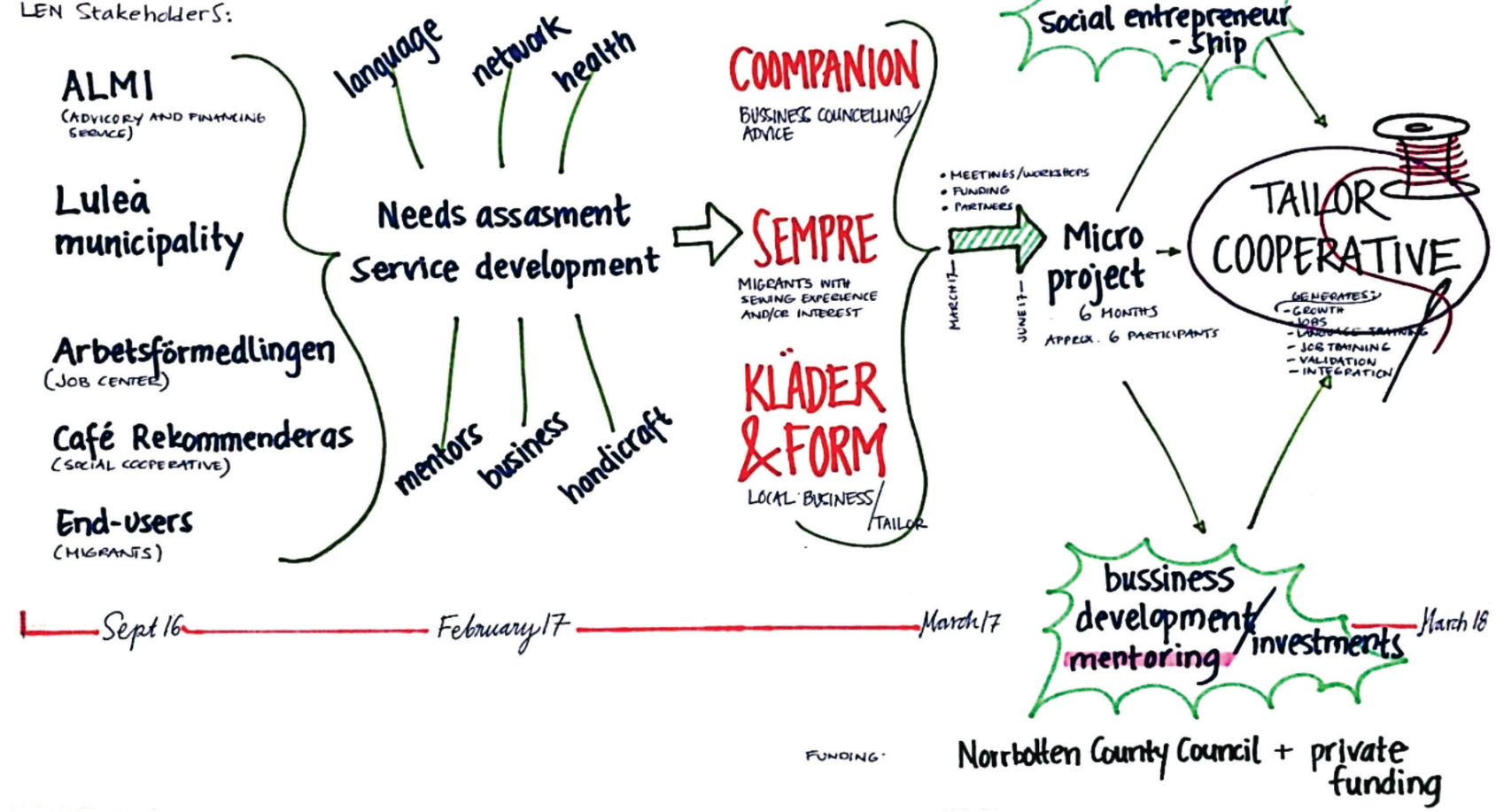

Above: The process of creating the Tailors' cooperative.

Below: A meeting of the Afghan Association members in Kokkola.

A community-initiated and self-run Afghan Association in Kokkola, Finland

In Kokkola, a group of Afghan migrants developed a plan for starting an Afghan Association as part of the SEMPRE project. The group applied for a start-up grant from the Funding Centre for Social Welfare and Health Organisations, which enabled them to rent a community space. Today, the association is run entirely by the migrants themselves. The association's activities include support in studying English/Dari, child care and an art club. The community space also functions as a hub for informal get-togethers. The process of developing and running an association has helped the migrants to acquire new skills and learn about the democratic principles of running an organisation. One of the representatives of the Afghan Association was invited to become a member of the Multicultural Council in the City of Kokkola, making it possible for them to be involved in and influence decision-making.

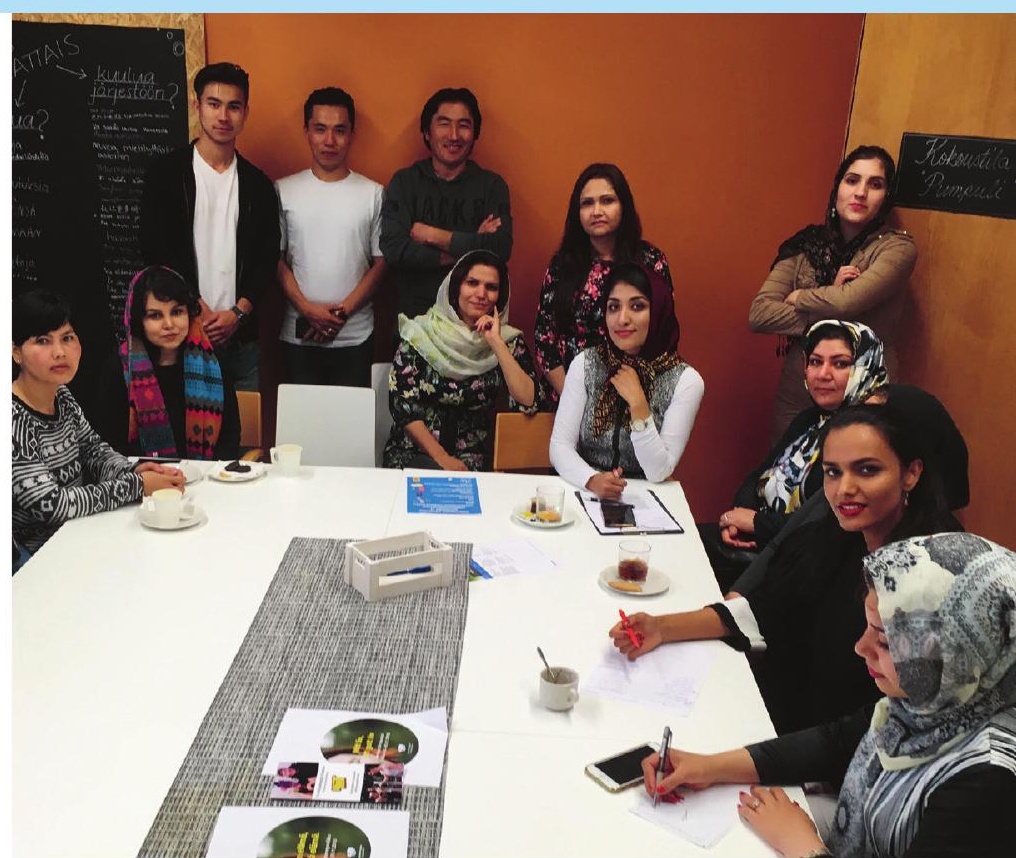




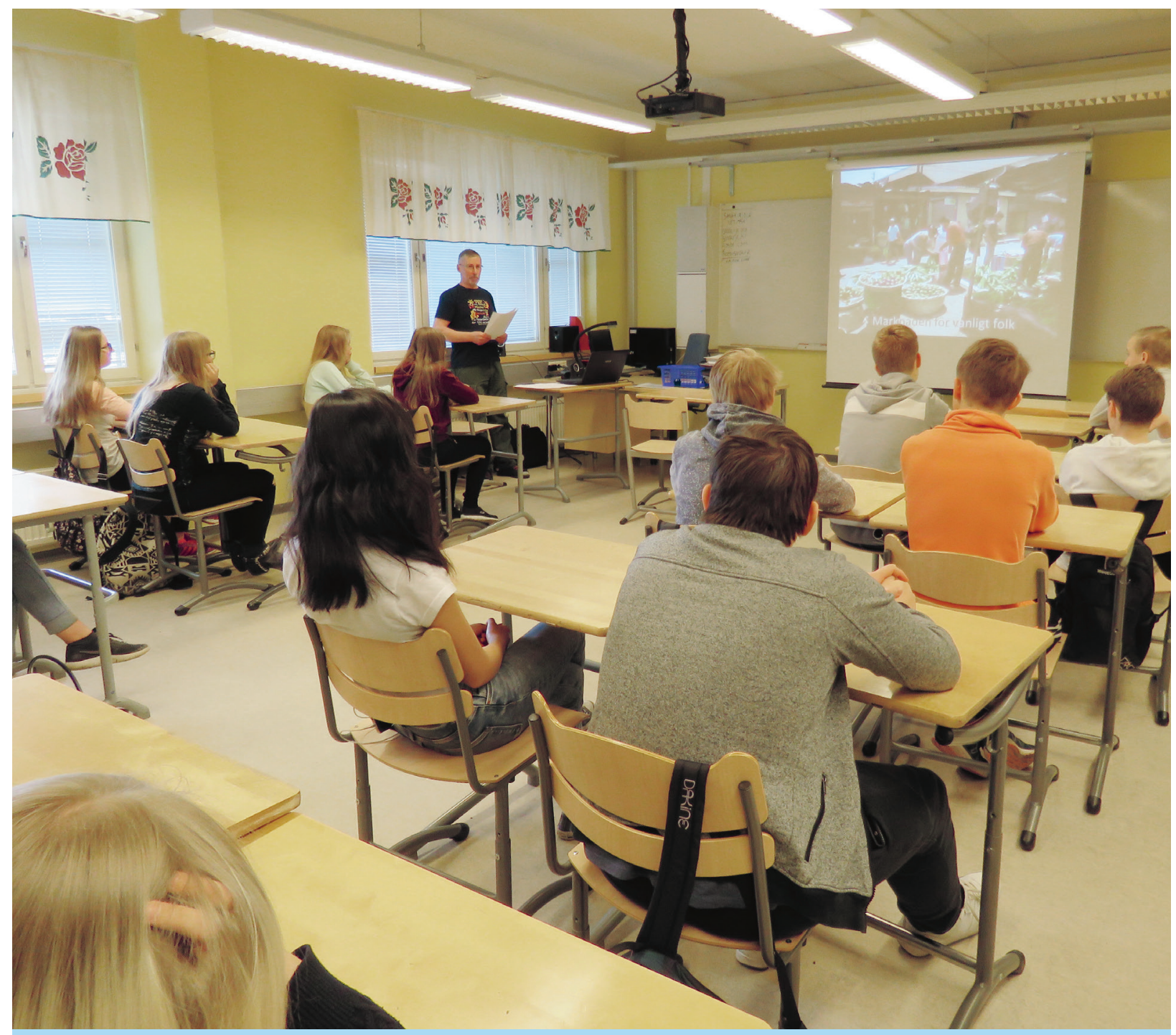

Above: Intergenerational meetings in Korsholm are empowering both older adults and students. Below right: Older adults sharing their expertise at a school in Korsholm.

Older adults as guests and experts at school in Korsholm, Finland

In cooperation with a secondary school in Korsholm, a micro project called 'Guest at School' was initiated. The project aimed to develop intergenerational meetings where older adults could share their knowledge and competences with teenagers, in both professional and private life. The micro project received positive feedback from everyone involved, with one of the teachers referring to the initiative as 'a gold mine in teaching'. Whether these activities will continue once the project ends remains to be seen. In addition to the enthusiasm of the older adults, this project requires an engaged facilitator from the school, and it is not yet clear who will take on this role.

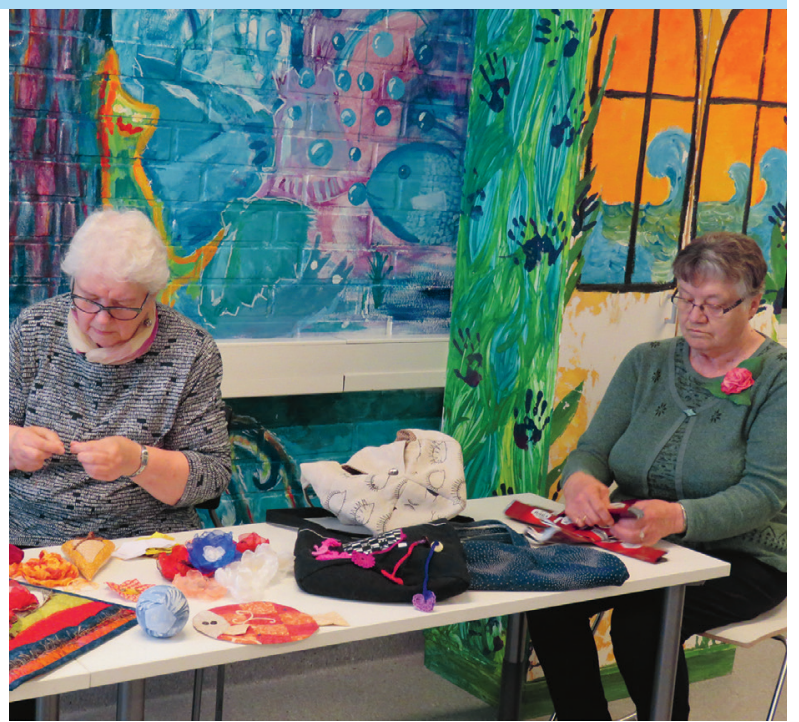




\section{KEY LESSONS LEARNED FROM THE SEMPRE PROJECT}

- Even though not all micro projects reached a level of maturity to become self-sustaining initiatives within the project's lifetime, they have contributed to building up social capital (i.e. networks, relationships and trust among actors) in rural areas, improved the life circumstances of vulnerable groups and contributed to their empowerment and mobilisation.

- In order to achieve sustainable and long-term change, user involvement should be combined with changes in those organisational and social structures that affect the quality of life and well-being of the individuals (Lindberg, 2018). User involvement should be integrated as a working method by social service providers, embedded in the organisational processes and practice and facilitated by the enabling policy environment.

- It is crucial that user involvement is taken seriously. Service users' opinions should be valued, and their voices allowed and listened to. Involvement can vary considerably (see the participation pyramid in the figure below). In some cases, users gain access to organisations and decision-making structures and have a real say in them. If user involvement is mere lip-service, however, it can result in frustration and disempowerment - the opposite of its genuine intention, which is to be liberating, participatory and appreciative (read more about introducing service-user involvement into organisational practice in the Organisational Roadmap for Social Service Providers ${ }^{3}$ ).

- A multi-stakeholder approach is crucial for addressing complex challenges in rural areas. SEMPRE has engaged and mobilised local community actors, including service-users, public authorities and nonprofit organisations in 11 Local Empowerment Networks throughout the Baltic Sea Region with the purpose of improving the coordination of activities and resources while addressing joint challenges.

\section{Participation pyramid by Straßburger and Rieger}

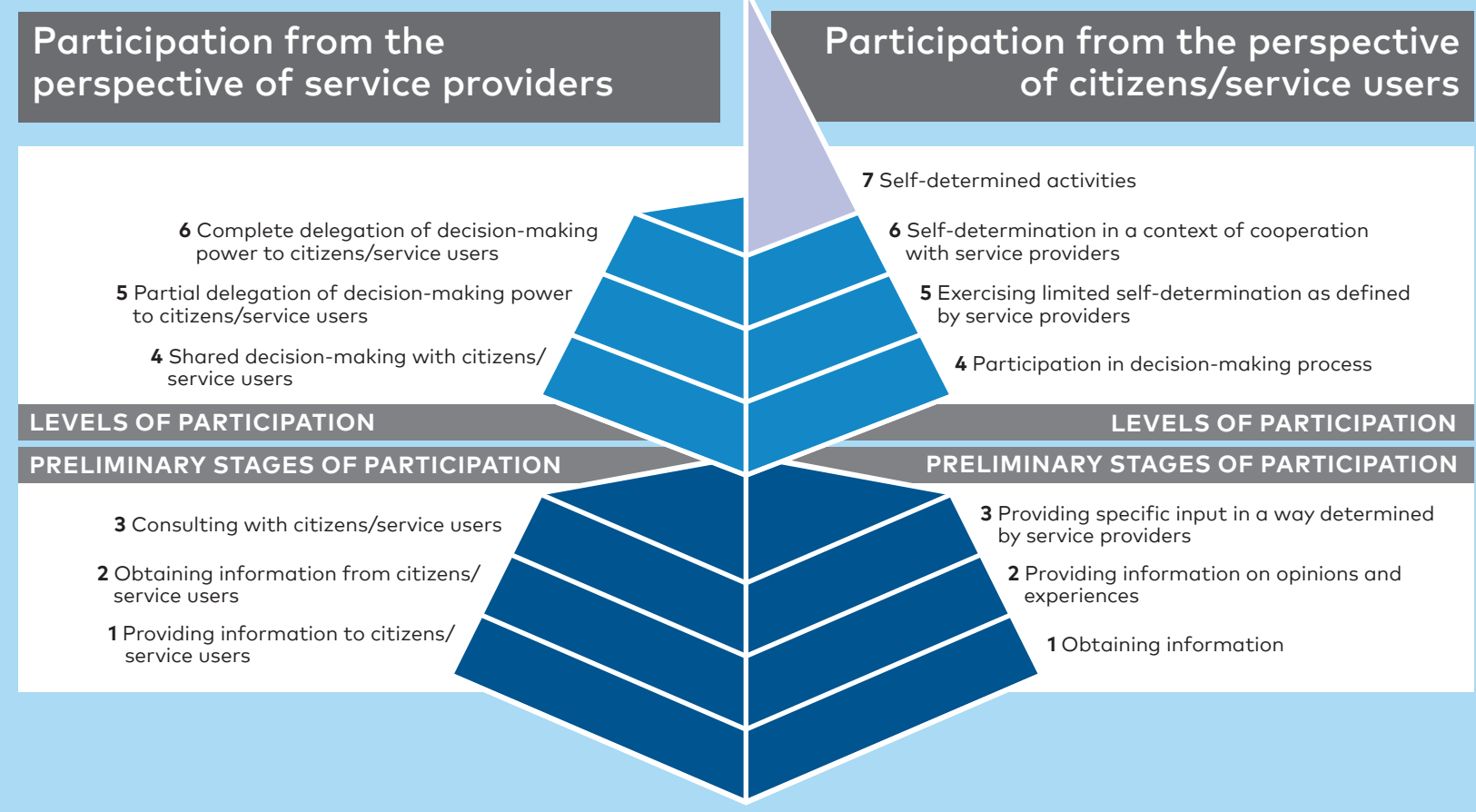

(c) Quelle: Straßburger/Rieger (Hg.) Partizipation kompakt - Für Studium, Lehre und Praxis sozialer Berufe 2014: S.232f 


\title{
POLICY RECOMMENDATIONS
}

\author{
How can we build empowering environments that value \\ the knowledge of service users and foster the co-production \\ of social services together with the users?
}

00000000000000000000000000000000000000000000000

\section{RECOMMENDATIONS FOR SERVICE- PROVIDER ORGANISATIONS}

1. Skills and competencies development

- Strengthen the capacity and skills of social service provider staff to implement service-user involvement Too often, the service provider's staff do not have the knowledge, skills and competencies that they need to step out of their usual thought and work patterns. It is therefore important for service-provider organisations to support their staff in developing the skills needed and make resources available in terms of time and finance.

\section{Encourage (trans)national exchange and peer} learning

Mutual visits and study tours are good opportunities to learn and to encourage the transfer of good solutions and practices to other organisations. Service providers have the means to facilitate contacts and twinning between organisations.

\section{Service-user involvement as part of organisational practice}

Introduce service-user involvement as an integral part of organisational practice

To accommodate user involvement, service-provider organisations require a supportive leadership that embraces service-user participation and involvement. One possible way to strengthen leadership and create commitment in the long run is to become involved in and support strategic networking between organisations engaged in a change process in order to encourage the exchange of experiences and organisational peer learning.

Employ service users as members of staff at social service providers

Employing or providing a role for former or current service users is a way to contribute to their empowerment and recognise their value. Service users can be engaged as staff members, facilitators, mentors or supporters. Former service users can bring specific knowledge to the organisation and act as door-openers.

\section{Small-scale piloting}

Service providers can use their resources to finance innovative pilot solutions for social provision that ensure strong service-user involvement. Piloting on a small scale is a good way to establish whether a solution has the potential to grow or 'fail fast', while using the minimum of resources.

- Support service users in the process of establishing user-led organisations

Another way to increase service-user involvement and empowerment is to support user-led initiatives. Service providers can facilitate this process by offering coaching and capacity-building, providing space for meetings and lobbying efforts. For examples of userled initiatives see the Microproject Brochure.

\section{RECOMMENDATIONS FOR LOCAL/ REGIONAL/NATIONAL PUBLIC AUTHORITIES, POLICY-MAKERS AND OTHER RELEVANT ORGANISATIONS AND STAKEHOLDERS}

\section{Availability and appropriateness of funding mechanisms \\ - Make room for different funding mechanisms and instruments \\ The availability of different types of funding and mechanisms accommodating the needs and potential of different user-led initiatives is highly important. These funding instruments should allow different types of stakeholders and organisations to apply for funding, including loos-knot and informal groupings. Small-scale financial instruments, such as micro loansand fast cash ('snabba cash') financing by Boden Council7, are examples of good practice.}

\section{- Simplify the application and administration} procedures to make funding more accessible for smaller organisations such as NGOs, cooperatives and social enterprises

Language that is too complex and demanding, and bureaucratic application and project management processes are among the barriers faced by social service providers and service users wishing to apply for funding. 
2. An ecosystem for user involvement

- Use public procurement as a tool to support service-user involvement

Public procurement can be used to create an ecosystem that facilitates user involvement and participation. It can be used as a tool to encourage service-user involvement when signing contracts for the provision of public services and when buying products/services.

- Create a supportive environment for social service providers to adapt new work methods and manage organisational change

Creating a framework for social service providers to facilitate service-user involvement and encourage user-driven initiatives could entail various measures, such as providing training and capacity-building for social service providers and incorporating service-user involvement in social work education.

- Make sure that civil society organisations are not used as a substitute for social welfare services Fostering user-led initiatives should primarily be seen as a way to trigger social innovation, strengthen social capital and contribute to higher quality social service provision. Shifting full responsibility for service provision to civil actors should be avoided, as governments and public institutions have the primary responsibility for social services provision.

\section{Partnerships and network-building}

\section{- Mobilise multi-stakeholder partnerships}

User involvement practices and initiatives driven by service users to tackle complex societal problems have a greater potential to succeed if they are anchored in a good network of local and regional partners. Multistakeholder perception of and devotion to the issues addressed may open new avenues for funding and facilitate the sharing of power and responsibility. This approach was successfully tested and implemented in the SEMPRE project, as part of which Local Empowerment Networks (LENs) were formed as structured platforms for cooperation (read more on page 2).

\section{RECOMMENDATIONS FOR EU POLICY- MAKERS AND INSTITUTIONS}

\section{A stronger focus on the social dimension in EU policies and programmes \\ - Add socially-responsible criteria to the EU procurement rules \\ The EU procurement rules already allow for social considerations so long as the principles of value for money and equal access for all EU suppliers are observed. Adding and enforcing more socially}

responsible criteria would make public procurement a strategic tool to influence society in a more inclusive and socially sustainable way.

- Encourage closer focus on the social dimension in EU policies and programmes

Social innovation has not been acknowledged significantly in European strategic thinking, particularly in the ERDF; and social criteria are missing from the programme description. Future Interreg programmes should better acknowledge the value of the social dimension for European regional development and territorial cooperation by putting technological and social innovation on an equal footing. Social innovation should get a proper place and recognition in the EU Strategy for the Baltic Sea Region and its current action plan.

\section{Descriptive indicators to measure societal outcomes}

- Improve the way societal outcomes are measured by including descriptive indicators

It is important to calculate the added value of projects in terms of societal outcomes. This requires the development of an appropriate descriptive indicators framework, as quantitative indicators fail to measure the quality of a product or a service. Future Interreg programmes should allow for greater flexibility in terms of indicators in order to accommodate social perspectives when measuring project progress. One solution could be to allow each project to come up with a set of relevant descriptive indicators to measure its progress.

\section{Interreg programmes post 2020 \\ - Allow pre-financing of Interreg projects}

The lack of start-up funding for Interreg projects is a major barrier to participation for smaller organisations, as they are required to carry out project activities for up to 14 months before they receive their first payment. A proportion of the project budget should be made available to partners before the project implementation phase. This will open up opportunities for more diverse actors to become involved in the projects and in the Interreg programme. 


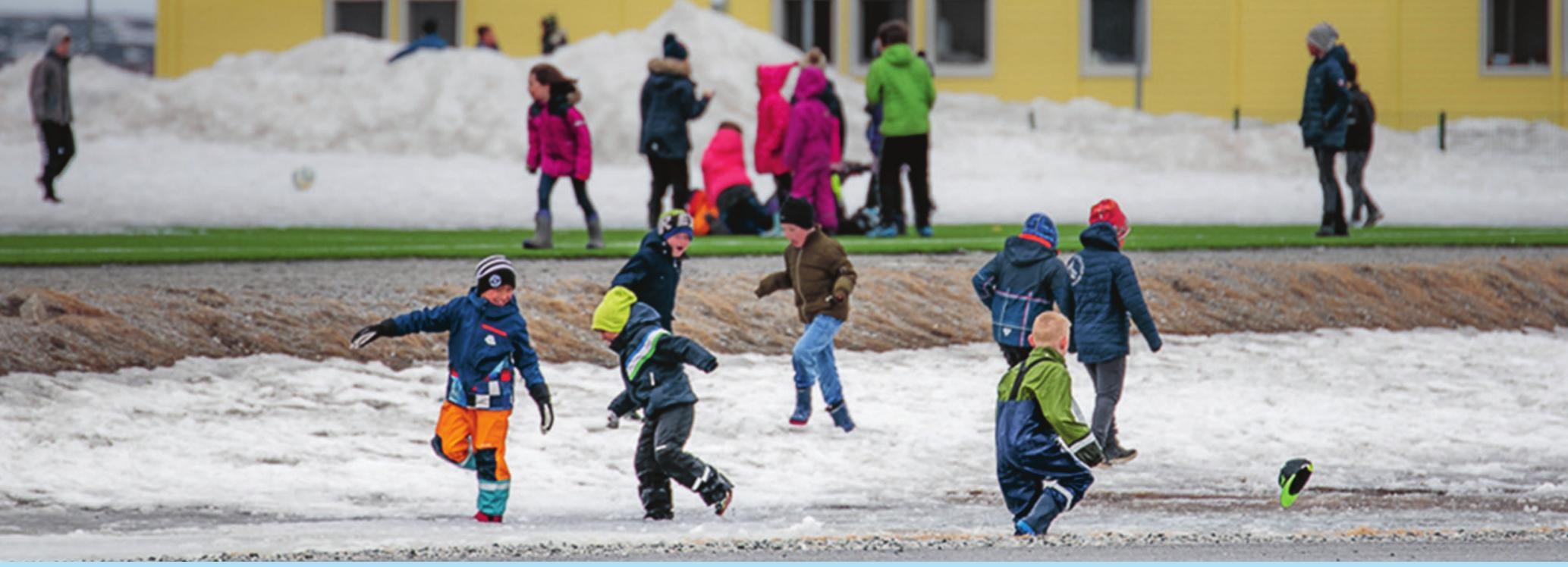

Children are the backbone of thriving rural communities.

\section{ENDNOTES}

${ }^{1}$ http://www.sempre-project.eu/handbook

${ }^{2}$ http://www.sempre-project.eu/micro-projects

${ }^{3}$ http://www.sempre-project.eu/roadmap

${ }^{4}$ For information on how to support the organisational change process, see the SEMPRE Organisational Roadmap for Social Service Providers.

${ }^{5}$ http://www.sempre-project.eu/micro-projects

${ }^{6}$ https://boden.enamnd.se/oversikt/overview/375

\section{REFERENCES}

Beresford P (2016) All Our Welfare: Towards Participatory Social Policy. Policy press.

Copus A., Perjo L., Berlina A., et al. (2017) Social innovation in local development: Lessons from the Nordic countries and Scotland.

Lindberg M (2018) Promoting and sustaining rural social innovation. European Public \& Social Innovation Review 2(2): 30-41.

\section{ABOUT THIS POLICY BRIEF}

This policy brief is based on the SEMPRE project which promotes empowerment in social service provision in rural areas of the Baltic Sea Region.

Read more: http://www.sempre-project.eu/

\section{Research contacts}

Anna Berlina

anna.berlina@nordregio.org

Gustaf Norlén

gustaf.norlen@nordregio.org

\section{Photos:}

Frontpage: Frida Larsson

Page 3: Figure by Helen Nilsson

Page 3: Afghan Association picture source :

Johanna Hiitola

Page 4: Susanne Jungerstam

Page 8: Mats Bjerde

ISSN 2001-3876

DOI: doi.org/10.30689/PB2019:2.2001-3876

www.nordregio.org
.

Baltic Sea Region

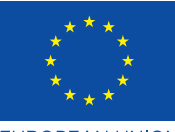

EUROPEAN REGIONAL DEVELOP EUROPEAN UNION 